Alice Rocha da Silva ${ }^{1}$

Cayo César Morais dos Santos ${ }^{2}$
Recebido em: 23/03/2016.

Aprovado em: 23/03/2016.

1 Doutora em Direito Internacional Econômico pela Aix-Marseille Université, França, (revalidado pela Universidade Federal do Ceará - UFC). Mestrado em Direito das Relações Internacionais pelo UniCEUB. Graduação em Direito pelo UniCEUB e Graduação em Relações Internacionais e Ciência Política pela Universidade de Brasília-UnB. Professora da Graduação e Pós-graduação stricto sensu em Direito do Centro Universitário de Brasília (UniCEUB) e da Faculdade Processus. E-mail: rochaalice@yahoo.com.br.

2 Mestrando do Programa de Pós-Graduação stricto sensu em Direito do Centro Universitario de Brasilia (UniCEUB).

\section{Migração, segurança internacional e direitos humanos: os desafios a serem enfrentados e reflexões sobre a contribuição do direito administrativo global*}

\author{
Migration, international security and \\ human rights: challenges and reflections \\ about the contributions of global \\ administrative law
}

\section{Resumo}

A migração tem se tornado um fenômeno que não respeita fronteiras ou conceitos clássicos de soberania estatal, necessitando de novos instrumentos para tratamento dessa problemática. O presente artigo busca analisar o contexto migratório internacional sob a perspectiva das questões do emprego e previdência, e da criminalidade, com ênfase no tráfico de pessoas e no terrorismo. Entre os objetivos do estudo está a reflexão sobre a busca de um melhor entendimento desse processo que tende a avaliar a questão migratória como um problema de segurança e elucidar pontos pertinentes a tal problemática, indicando que a melhor solução para o problema é o acolhimento e a regularização da situação dos imigrantes, por vias já utilizadas ou por novos instrumentos e parâmetros oferecidos pelo Direito Administrativo Global.

Palavras-chave: Migração. Segurança internacional. Direitos humanos. Direito administrativo global.

\begin{abstract}
Analysis of international migration context from the perspective of the issues of employment and social security and crime, with an emphasis on human trafficking and terrorism. The purpose of this article, therefore, is to reflect in search of a better understanding of this process that tends to evaluate the migration issue as a security problem and elucidate relevant points to this issue, stating that the best solution to the problem is the host and regularizing the situation of immigrants. Addresses also reflections on Global Administrative Law's contribution to the present time of global migration crisis.
\end{abstract}

Keywords: Migration. International Security. Human Rights. Global Administrative Law's. 


\section{Introdução}

Com a queda do famigerado muro de Berlim no ano de 1989, mítico e simbólico ato de encerramento do processo iniciado pela Perestroika, do então presidente soviético Mikhail Gorbachev, que levaria ao término da Guerra Fria - décadas de disputas econômicas, ideológicas e militares entre o bloco capitalista, comandado por Estados Unidos e o socialista, dirigido pela União das Repúblicas Socialistas Soviéticas (URSS) a partir da polarização iniciada com o término da Segunda Grande Guerra -, é possível verificar um crescente processo de mudança das realidades de segurança internacional cujos problemas e questões ampliaram-se com o fim daquela contenda bipolarizada. Até então, a ênfase de segurança internacional ainda estava bastante contida nas preocupações de índole tradicionalmente militar e eram definidas como questões de segurança de Estado, em especial ante ao temor de utilização de arsenais nucleares capazes de produzir destruição generalizada e global.

O mencionado processo de transformação da segurança internacional ganha contornos ainda mais dramáticos a partir do inimaginável evento da queda das Torres Gêmeas, em 11 de setembro de 2001, fazendo com que, muitas vezes, as concepções de criminalidade e de migração sejam confundidas sob o prisma da gestão de segurança criando políticas que privilegiam o valor "segurança nacional" em detrimento dos direitos humanos. ${ }^{3}$

3 Nesse sentido HYATT, Susan B. What was neoliberalism and what comes next? The transformation of citizenship in the law-and-order State . In: SHORE, Cris; WRIGHT, Susan; PERÒ, Davide (Ed.). Policy worlds: anthropology and the analysis of contemporary power. New York: Berghahn Book; Oxford, 2011. p. 106 "Of course, no particular date, 9/11 included, can ever be asked to represent a definitive end point for any era (or a beginning point for any other); however, 9/11 marks the moment where the public discourse in the U.S.A. and elsewhere moved decisively away from the free market-oriented mantras of neo-liberalism and towards the increased invocation of such alternative values as 'safety', 'security', 'control', 'containment' and 'protection"'- tradução livre: "Naturalmente, nenhuma data específica, 11/09 inclusive, pode sempre ser considerada representativa de um ponto final definitivo para qualquer época (ou um ponto de partida para qualquer outra); no entanto, 11/09 marca o momento em que o discurso público nos EUA e em outros lugares mudou-se decisivamente, para longe dos mantras do neo-liberalismo voltados para o livre mercado e passando a fomentar a invocação de valores alternativos tais como 'salvaguardas', 'segurança', 'controle' , 'contenção' e 'proteção' - Disponível em: <http:// www.academia.edu/7093111/What_Was_Neoliberalism_ and_What_Comes_Next>. Acesso em: 5 ago. 2015.
Desde as ocorrências iniciais em Nova York, até as mais recentes em Paris ${ }^{4}$, percebe-se o forte incremento na noção de segurança nos países receptores do fenômeno migratório, com ênfase no que essas nações convencionaram denominar "novas ameaças", referindo-se às questões de segurança nacional e internacional. Dentre as diversas problemáticas envolvendo o tema, optou-se por estabelecer o foco em emprego, previdência e criminalidade, especificamente no que se refere ao tráfico de pessoas e condutas paralelas, e ao terrorismo.

Nesse sentido, a definição de segurança estatal ou nacional utilizada nesta análise possui um caráter amplificado e de dimensões mais profundas uma vez que as ameaças já não se restringem à possibilidade de um ataque militar a partir de uma nação estrangeira, cuja origem é bastante verificável, visto que se trata de outro Estado, mal ou bem, sujeito à ordem política internacional. Ao contrário, tais ameaças passam a ser indeterminadas, espécies de agressão que podem vir, inesperadamente, de organizações não estatais, criminosas ou terroristas. Além disso, a própria lógica das respostas possíveis aos Estados agredidos também passará a diferir bastante daquela que se daria no contexto das agressões ou ameaças tradicionais militares.

Todo esse ambiente produz consequências bastante relevantes para o contexto migratório internacional, com a tendência de um tratamento cada vez mais rigoroso sob o ponto de vista da segurança do Estado receptor, situação que se estende, igualmente, à realidade dos blocos regionais. A partir desse rigor em prol da segurança, o risco efetivo é de que também haja um incremento na visão preconceituosa em relação ao imigrante, no que toca ao chamado "roubo" de postos de trabalho e decorrentes problemas previdenciários.

O fenômeno multifacetado da globalização, que facilita e incrementa ondas migratórias entre as nações, produz, também, como consequência preocupante, pela ótica da segurança, a diluição e porosidade das fronteiras, exacerbando as limitações da atuação preventiva e fiscalizadora dos Estados. Nesse viés, as migrações, as fronteiras e a segurança se interconectam apontando os novos

4 Nesse contexto sobressaem os ataques terroristas à cidade de Paris, primeiro, o atentado à sede do jornal satírico Charlie Hebdo, em janeiro de 2015 e, ainda mais recentemente, os múltiplos atentados perpetrados em diferentes e estratégicos pontos da Cidade Luz, no mês de novembro de 2015. 
desafios à efetiva propagação dos direitos fundamentais dos atores humanos destes fluxos migratórios.

Em tal contexto de complexidade, é possível discernir que os mecanismos políticos tradicionais para elaboração da regulamentação legal dessas novas situações migratórias deixam a desejar, em especial em relação ao critério da agilidade para a formatação de uma ordem jurídica específica para o contexto migratório mundial, notadamente, em tempos de crises profundas nas fronteiras da Europa em face dos fluxos migratórios ocasionados pela violência e guerras nas regiões do oriente médio.

Nesse sentido, a proposta é de que o Direito Administrativo Global, com sua notável ênfase de integração entre os setores público e o privado, a leveza de sua regulamentação e sua agilidade para construção de respostas efetivas, sem os entraves da política e burocracia tradicionais, poderá contribuir para equalização dessa nova realidade migratória internacional.

As hipóteses que nossa reflexão apresenta podem ser resumidas em: a) existe uma forte tendência para o tratamento da questão migratória como um problema de segurança; b) o tratamento humanitário e a regularização efetiva da situação do imigrante é a forma mais adequada de lidar com a complexa questão migratória internacional e, c) o Direito Administrativo Global possui dinâmica própria e mecanismos adequados para a produção de soluções mais ágeis para a crise migratória atual.

Portanto, o objetivo do presente artigo é refletir em busca de um melhor entendimento desse processo que tende a avaliar a questão migratória como um problema de segurança não somente do ponto de vista militar e elucidar pontos pertinentes a tal problemática, ressaltando, contudo, que o recorte da análise se dará, tão somente, em relação às já mencionadas questões do emprego e previdência e o problema da criminalidade com ênfase no tráfico de pessoas e na questão do terrorismo.

\section{0 reflexo da presença do migrante}

O tratamento da problemática da segurança envolvendo imigrantes pode ser visto de uma perspectiva mais ampla do que a tradicional menção a ameaças militares. Nesse sentido, vale discutir a interferência de políticas migratórias em setores como emprego e previdência, mas também no que se relaciona com a criminalidade reforçada pela situação de vulnerabilidade dessas pessoas que podem virar vítimas de ações de tráfico de pessoas ou terrorismo.

\subsection{Modificações positivas no contexto de oferta de empregos e previdência}

Um dos grandes receios que envolvem a questão migratória em todo o mundo, gerando um ambiente de tensão entre os habitantes natos e os migrantes, é o temor dos cidadãos locais de perderem seus postos de trabalho. Outra relevante questão, sob o prisma dos Estados receptores da imigração, é o equilíbrio e manutenção de seu sistema previdenciária ou de seguridade. Essa dificuldade tem sido apontada comumente como um dos fortes argumentos para que o tratamento da pessoa imigrante seja estabelecido com bastante ressalva pela autoridade migratória.

Não obstante, o processo de internacionalização característico da globalização, com seu incremento de fluxos financeiros, investimentos produtivos diretos, movimentação de mercadorias, intercâmbio tecnológico, avanço de comunicações e troca de informações, produz uma outra necessidade de índole internacional, qual seja, o trânsito de trabalhadores pelas fronteiras dos países. $\mathrm{O}$ enorme desafio, assim, é que os Estados precisam adequar suas políticas públicas para que, enquanto absorvem o potencial produtivo da chegada desses trabalhadores, a questão do emprego, de igual modo, possam garantir a esses imigrantes condições dignas de trabalho e incorporação aos sistemas de seguridade social, o problema previdenciário.

Relativamente ao emprego, a lógica do argumento contrário ao tratamento igualitário e humanizado do imigrante, em curtas palavras, seria a seguinte: "O emprego está nas mãos do imigrante, se não estivesse, necessariamente, estaria com um trabalhador nativo". De fato, num exame perfunctório da questão, essa lógica parece correta, porém, não resiste a um exame mais aprofundado de suas bases. Isto porque a noção de que há apenas uma quantidade limitada de empregos, ou trabalho, e que ninguém consegue uma posição no mercado de trabalho sem tirá-la de outra pessoa revela um equívoco oriundo da simplificação da análise econômica. Tal equívoco tem sido nominado por especialistas da área econômica como a Falácia da Escassez do Trabalho 5 .

Termo derivado da expressão em inglês "Lump of labour fallacy: The assumption that the quantity of labor required in an overall economy is fixed. This assumption in often regarded as fallacious, as the consensus view amongst economists today is that the quantity of labor demanded varies with respect to many factors. Foremost, these economists argue, employment of labor can expand the overall size 
Argumentam, referidos estudiosos da economia, que não se pode raciocinar, em relação a empregos, com a mesma lógica utilizada para mercadorias ou produtos em geral. Ou seja, não é possível comparar a relação de consumo pertinente a produtos com a relação entre oferta e procura de mão de obra para postos de trabalho. É certo que o aumento da oferta de um determinado produto, por exemplo, uma superprodução de tomates, afetará o preço desse produto com a diminuição do seu valor e, por outro lado, a escassez gerada pela quebra da safra acarretará uma valorização pela dificuldade de encontrar o produto, aumentando o seu preço.

Contudo, trabalhadores (ou imigrantes em nosso caso) não podem ser comparados a produtos, uma vez que a sua presença no mercado de trabalho, embora efetivamente aumente a oferta de mão de obra, por outro lado e ao mesmo tempo, faz aumentar a demanda por novos tipos de mão de obra, por exemplo, quando passam a utilizar o seu salário para consumir novos produtos ou serviços, como cortar o cabelo ou comprar um novo aparelho de televisão e, assim, na medida em que aumentam o consumo, também pressionam a demanda por novos postos de trabalho no salão de beleza, ou na indústria de equipamentos eletrônicos. Demais disso, é conhecimento cediço no pensamento econômico o aumento do tamanho da população incrementa, igualmente, o tamanho da economia.

Outra reflexão cabível em contraposição ao pensamento de que a presença do imigrante rouba os empregos dos locais é imaginar que essa premissa seria correta relativamente aos jovens que saem do sistema educacional para o mercado de trabalho. Não nos parece nada razoável argumentar que referidos jovens estão roubando o emprego dos mais velhos, já colocados no mercado de trabalho. Essa linha de pensamento é incorreta ou, no mínimo, extremamente simplista.

A presente pesquisa possibilita observar que, ao menos em sua maioria, os argumentos contrários à imigração ou ao tratamento humano da pessoa do imigrante caracteriza uma variação da Falácia da Escassez de Trabalho. Conquanto não tenhamos encontrado estudos específicos dessa questão no ambiente nacional em que, quer

of the economy, leading to further job creation. Reducing the amount of labor employed would decrease overall economic activity and thus further decrease the demand for labor." Disponível em: <http://www.investopedia.com/terms/l/lump-of-labour-fallacy.asp >. Acesso em: 31 jul. 2015. nos parecer, o tema não tenha sido abordado expressivamente, há, no contexto norte-americano, estudos contundentes que revelam que, na realidade empírica, essa percepção não se sustenta.

Destacamos, em continuação, alguns desses referidos estudos, que buscam refutar a falácia da escassez. $\mathrm{O}$ primeiro, considerado um marco na análise da questão, é o trabalho The Impact of the Mariel Boatlift on the Miami Labor Market ${ }^{6}$, publicado por David Card, professor de economia da Universidade da Califórnia em Berkeley, examinando o impacto de um evento migratório que foi designado como o "êxodo marítimo de Mariel”.

Trata-se, em resumo, de uma migração em massa ocorrida no ano de 1980, quando um enorme grupo de mais de 125 mil imigrantes cubanos deslocou-se para a cidade de Miami, aproveitando-se de uma autorização temporariamente concedida pelo governo de Cuba. Desse total, cerca de 45 mil imigrantes com idade produtiva fixaram residência naquela cidade. O estudo de Card revelou que não houve qualquer impacto negativo, seja no valor dos salários, seja na manutenção dos empregos, para as pessoas que já trabalhavam em Miami, apesar do incremento de cerca de $7 \%$ na oferta de mão de obra que a chegada dos 45 mil cubanos significou num período de 4 meses após a chegada dos imigrantes.

A grande importância dada a este estudo, como afirmado anteriormente, é que se trata da primeira análise científica a modificar os paradigmas tradicionais que assumiam a falácia da escassez de trabalho como certa. Anteriormente, a conclusão comum era no sentido de que os imigrantes traziam benefícios apenas em longo prazo, porém, à custa de penosos prejuízos em curto prazo. A partir do estudo de Card, contudo, consistentes trabalhos têm sido realizados para demonstrar que os benefícios se dão, realmente, em longo prazo, porém, sem grandes efeitos negativos imediatamente, modificando o consenso dos economistas sobre esta questão.

Outros estudos que defendem semelhante linha de pensamento, publicados por Giovanni Peri, da Universidade da Califórnia em Davis, hoje considerado um dos principais pesquisadores da temática migratória, demonstram que a força de trabalho trazida para os países

CARD, David. The impact of the mariel boatlift on the Miami labor market. Industrial and Labor Relations Review, v. 43 , n. 2 , p. $245-257$, jan. 1990 . Disponível em: <http:// davidcard.berkeley.edu/papers/mariel-impact.pdf $>$. Acesso em: 31 jul. 2015. 
de acolhimento pela migração tende a complementar, e não competir, com a força de trabalho preexistente. $\mathrm{A}$ pesquisa de Peri ${ }^{7}$ aponta para duas conclusões bastante robustas: a) a presença do imigrante não afeta, ao contrário do pensamento comum, as vagas de emprego dos cidadãos nacionais ${ }^{8}$ e b) a presença dos imigrantes auxilia no aumento da produtividade e crescimento econômico do país hospedeiro. ${ }^{9}$

Os estudos de Peri, aliás, têm sido a base conceitual do projeto para a modificação das políticas administrativas para migração, proposta pelo governo democrata do presidente Barack Obama, nos Estados Unidos, cuja conclusão é no sentido de que o programa de legalização em larga escala dos imigrantes terá um grande impacto no crescimento na economia americana, e na produtividade a partir de fatores como o emprego e os salários, bem como nos investimentos e na questão fiscal. ${ }^{10}$

A mesma conclusão é alcançada em estudos distintos de outros pesquisadores, com destaque para os trabalhos de: a) Gihoon Hong e John MacLaren que concluem quanto ao tema que as evidencias apontam para o fato de que os imigrantes parecem aumentar os salários em locais de baixa comercialização e atrair, inclusive, trabalhadores nativos, beneficiando, portanto, os trabalhadores locais ${ }^{11}$ e b) Rachel Firedberg e Jennifer Hunt que

Disponível em: <http://www.nber.org/papers/w16332. pdf $>$. Acesso em: 1 ago. 2015. e Disponível em: <http:// www.cream-migration.org/publ_uploads/CDP_07_15. pdf $>$. Acesso em: 1 ago. 2015.

8 "This, in turn, explains the counter intuitive fact that there is a zero correlation between immigration and wage and employment outcomes of natives". In: Work Papers Series Department of Economics UCDAVIS: Rethinking the area approch: Immigrants and teh Labor Market in Califronia, 1960-2005. Disponível em: <http://wp.econ.ucdavis. edu/09-13.pdf>. Acesso em: 1 ago. 2015.

9 FURCHTGOTT-ROTH, Diana. Immigrants make the economy more efficient by increasing the supply of labor, both in hight an low-skill áreas, creating jobs for native-born Americans in the process: a 2010 reserarch by Peri, with Chad Saparber of Colgate University, concluded that - contrary to popular wisndon - immigrants do not, in fact, displace native workers." In: E21 Issue Brief. Manhatan Institute Rewiew, New York, n. 2, dez. 2014, p. 3. Disponível em: <http://www.manhattan-institute.org/pdf/ e21_02.pdf >. Acesso em: 1 ago. 2015.

10 Nesse sentido ver "The Economic Effects of Administrative Action on Immigration", elaborado pelo Conselho Econômico do Escritório Executivo do Presidente dos Estados Unidos em novembro de 2014. Disponível em: <https:// www.whitehouse.gov/sites/default/files/docs/cea_2014_ economic_effects_of_immigration_executive_action.pd $>$. Acesso em: 1 ago. 2015.

11 HONG, Gihoon; MACLAREN, John. Immigrants appear apontam, no âmbito da Europa, além das mesmas conclusões quanto aos benefícios da presença dos imigrantes no mercado de trabalho, o fato de que apenas para a hipótese particular dos imigrantes ilegais é que se pode constatar a diminuição do nível salarial dos trabalhadores locais $^{12}$. Tal conclusão indica que os esforços de legalização do imigrante podem ser o caminho para garantia e potencialização dos benefícios de sua presença no pais acolhedor.

Portanto, relativamente ao problema do emprego, podemos concluir que os temores pertinentes à presença e acolhimento do imigrante não se justificam. Ao contrário, parece que a legalização desta presença possibilita impactos positivos para a economia e para o incremento da produtividade e, consequentemente, para os empregos e salários, seja dos habitantes locais, seja, é óbvio, para a própria situação do imigrante.

Outro aspecto configurador de certa apreensão a propósito do fenômeno migratório mundial é a questão da previdência e seguridade social. Trata-se de questão de altíssima complexidade em todo o mundo e, por conseguinte, não é o objetivo do presente trabalho analisá-la com a profundidade que requer. Não obstante, assim como acontece em relação ao emprego, entendemos que é importante anunciar que se trata de problema que tem relevante influência na análise da situação migratória internacional. Mais uma vez, destaca-se a grande influência da globalização que impulsiona o fluxo de mão de obra em nível internacional.

A questão da seguridade e previdência social, inicialmente tratada sob a ênfase do Estado nacional, ganha dimensões muito mais abrangentes na esfera internacional, atingindo, assim, os grandes fluxos migratórios do

to raise local non-tadables sector wages and to attract native-born workers form elsewhere in the country overall, it appears that local woerkers benefit form the arrival of more immigrants" In: NBER Working Paper Series. Are Immigrants a shot in the arm for the local economy? Cambridge, MA: NBER, 2015. Disponível em: <http://www.nber.org/ papers/w21123.pdf>. Acesso em: 1 ago. 2015.

12 FIREDBERG, Rachel; HUNT, Jennifer. Immigration will lower the wage more if immigrants are prepared to work for less than natives, as seems possible in the case of illegal immigrants, for example: an influxo f such immigrants not only supply, but makes it more elastic. The Journal of Economic Perspectives, Nashville, EUA, v. 9, n. 2, p. 23-44, fev. 1995. Diponível em: <http://www.researchgate.net/ profile/Rachel_Friedberg/publication/4902369_The_Impact_of_Immigrants_on_Host_Country_Wages_Employment_and_Growth/links/00b7d53510a07bb20b000000. pdf $>$. Acesso em: 1 ago. 2015. 
ambiente globalizado. Nessa temática devem ser mencionados dois desafios: a) migrantes que adquirem um direito à aposentadoria no exterior e retornam ao país de origem; b) migrantes que trabalham em um pais por períodos muito curtos para adquirir a aposentadoria ou, ainda, os que trabalham de forma clandestina sem direito a qualquer tipo de previdência. São duas, também, as questões que exigem resposta dos sistemas previdenciários, a saber, a) a possibilidade de acumulação de direitos previdenciários; b) a garantia de uma previdência social básica para migrantes que não adquiriram esses direitos em razão de trabalharem na informalidade ${ }^{13}$.

Segundo o Ministério da Previdência Social, os Acordos Internacionais de Previdência Social inserem-se no contexto da política externa brasileira e são conduzidos pelo Ministério das Relações Exteriores, com a parceria da pasta previdenciária, e têm por objetivo principal garantir os direitos da seguridade social previstos nas legislações dos dois, ou mais, países envolvidos, aos respectivos trabalhadores e dependentes legais. ${ }^{14}$

A doutrina especializada também aponta o papel deste mecanismo contratual, como método de garantia dos direitos dos migrantes. Destacamos, exemplificativamente, o ensino de Helmut Schwazer, para quem:

os acordos criam a possibilidade de que o indivíduo que migre dentre países possa: (i) ter acesso à assistência médica, (ii) usufruir, em um país acordante, caso esteja em exercício de trabalho temporário ou, ainda, sob algumas condições especiais adicionais, benefícios do regime geral de previdência social do próprio país de origem; e (iii) requerer benefícios previstos no regime geral de previdência do país para onde o trabalhador emigrou, computando, para tanto, inclusive o tempo de contribuição no país de origem e, ainda, em alguns casos, o tempo de contribuição em países terceiros que, por sua vez, tenham acordo com qualquer dos Estadosparte do acordo em tela ${ }^{15}$

Oportuno destacar que, sob o ponto de vista da

13 BRASIL. Ministério da Previdência Social. Migrações internacionais e previdência social. 2007. p. 9. (Coleção Previdência Social - Série estudos, v. 25). Disponível em: <http://www.previdencia.gov.br/arquivos/office/3_081014-111404-830.pdf> Acesso em: 3 ago. 2015.

14 BRASIL. Ministério da Previdência Social. Acordos internacionais e previdência sócia: Brasil. 2007. p. 15. (Coleção Previdência Social - Série estudos, v. 14). Disponível em: <http://www.previdencia.gov.br/arquivos/ office/3_081014-111357-716.pdf>. Acesso em: 3 ago. 2015.

15 SCHWARZER, Helmut. Migrações internacionais e a previdência social. Informe de Previdência Social, Brasília, v. 16, n. 12, dez. 2004. p. 1-20. legislação de regência, o sistema brasileiro de apoio à questão previdenciária do migrante ${ }^{16}$ tem suporte nos preceitos constitucionais, em especial, os artigos $4^{\circ}$ e $5^{\circ}$ da Constituição Federal de 1988 que estabelecem os critérios e valores pertinentes às relações do Brasil com os demais países e a condição de igualdade de tratamento para todos os seres humanos, independentemente de sua origem ou nacionalidade. Há, também, importantes convenções da Organização Internacional do Trabalho - OIT, ratificadas pelo país, que cuidam do tratamento igualitário para trabalhadores imigrantes no âmbito do Estado brasileiro, bem como legislação ordinária pertinente ao tema dos acordos internacionais.

Podemos concluir esse tópico, então, sob uma positiva perspectiva de viabilidade de um tratamento mais digno para o problema previdenciário dos migrantes internacionais, com base nos critérios dos direitos humanos, considerando-se o vetor referencial da regularização das situações migratórias.

\subsection{0 envolvimento passivo e ativo do migrante em práticas criminosas}

\subsubsection{Tráfico de pessoas e outras condutas criminosas}

\section{contra o migrante}

$\mathrm{O}$ envolvimento passivo ou ativo do migrante em práticas criminosas é um desafio importante a ser enfrentado não só no ponto de vista nacional como internacional, visto que o efeito de certas práticas pode ultrapassar fronteiras. Relevante destacar, contudo, desde logo, que o problema do tráfico de drogas ilícitas que é de extrema intensidade neste ambiente do crime internacional, despontando como um de seus braços mais potentes e, muitas vezes, se posicionando como o financiador de várias outras vertentes da criminalidade organizada transnacional, não será objeto de exame no presente trabalho, devido a sua abrangência e o caráter limitado de nossa análise.

O objeto analisado nessa seção ficará limitado à problemática do tráfico de pessoas e condutas relacionadas ao terrorismo. Em relação ao tráfico de pessoas, trata-se de um fenômeno criminal marcado pela dinâmica de diversas situações fáticas que muitas vezes configuram outras tipificações delituosas internacionais.

Para o enfoque da presente pesquisa, é oportuna

Expressão que denota tanto a situação daquele que deixa o país (emigrante), quanto o que adentra em país diverso de sua terra natal (imigrante) 
a citação feita por Anderson e O'Connell Davidson ${ }^{17}$, de trecho do relatório Asian Migrant Yearbook $2000^{18}$, em que o Asian Migrant Center - AMC defende que o fenômeno da migração é o gênero dentro do qual se insere, apenas como uma espécie, o tráfico de pessoas. $\mathrm{O}$ argumento da referida organização é no sentido de que retirar o tráfico de pessoas do contexto das migrações é contraprodutivo para a luta por implementação dos direitos humanos dos migrantes, basicamente, porque: a) coloca a questão da migração sob o controle policial, com escassa preocupação pelos direitos humanos e, b) o tráfico de pessoas passa a ser utilizado politicamente por governos como forma de desenvolver políticas restritivas para migração.

A questão, de fato, é controversa. Há uma tendência, consoante argumentam as pesquisadoras citadas acima, de que os atores estatais queiram combater o tráfico de pessoas a partir da implementação de sistemas cada vez mais rigorosos de controles da migração. Do outro lado da equação, todavia, as organizações não governamentais que atuam na área rebatem esses critérios e afirmam que o aumento do controle policial das migrações fortalece e incrementa as agressões contra os imigrantes, favorecendo, assim, num ciclo vicioso, o tráfico que desejam combater. ${ }^{19}$

17 ANDERSON, Bridget; DAVIDSON, Julia O'connell. Save the children publications: trafficking: a demand led problem? a multi-coutry pilot study. Stockholm. 2002. Disponível em: <http://gaatw.org/publications/The\%20Demand\%20Side\%20part1.pdf>. Acesso em: 6 ago. 2015.

18 A citação no original é a seguinte, p. 7 de Trafficking - a demand led problem?: " It must be emphasised that migration is the general phenomenon, and trafficking is only a mode of migration. Over-emphasizing trafficking andtaking it out of context (in relation to migration) is strategically counter-pro-ductive in the fight for human rights because: (a) trafficking puts migration in a crime control, crime prevention context, rather than talking about migrants' human rights first and then talking about trafficking in the context of human rights; and (b) trafficking is being used by governments as a vehicle to develop more restrictive approaches to migration in general (AMC, 2000, p. 18, original emphasis)"

19 "While state actors often hold that trafficking can be combated through tougher immigration controls and enforcement, many non-state actors argue that there verse is true. So, for example, where the Italian Foreign Minister told a press conference during the Central European Initiative meeting in Trieste in November 2001 that "Cracking down on illegal immigration is one of our goals. Strengthening our efforts against human trafficking is essential in the fight for fundamental human rights", the International Labour Office argues that restrictive migration policies actually fuel markets for smuggling and trafficking of migrants (ILO, 2002)"- livre tradução: "Enquanto atores estatais muitas vezes sustentam que o tráfico pode ser combatido
Não obstante essa grande celeuma conceitual que envolve os atores do contexto migratório internacional de lado a lado, dificultando uma definição acerca do tráfico de pessoas, e das demais condutas criminais perpetradas contra a pessoa migrante, no início do ano 2000, por fim, foi disponibilizada para ratificação a Convenção contra o Crime Organizado Transnacional, conhecida como Convenção de Palermo, que tem por objetivo, nos termos de seu artigo primeiro: "promover a cooperação pra prevenir e combater mais eficazmente a criminalidade organizada transnacional". Referida Convenção de Palermo conta com dois protocolos anexos: a) Protocolo Adicional à Convenção das Nações Unidas contra o Crime Organizado Transnacional, relativo ao Combate ao Tráfico de Migrantes por Via Terrestre, Marítima e Aérea e, b) Protocolo Adicional à Convenção das Nações Unidas contra o Crime Organizado Transnacional Relativo à Prevenção, Repressão e Punição do Tráfico de Pessoas, em Especial Mulheres e Crianças.

Todo o conjunto já está devidamente incorporado ao ordenamento jurídico brasileiro ${ }^{20}$ e reúne o arcabouço conceitual necessário à compreensão das várias hipóteses criminais envolvendo a pessoa do migrante, inclusive, o tráfico de pessoas. É a partir desse novo contexto normativo das Nações Unidas que se tornou possível esclarecer: o que é o tráfico de pessoas; quais as suas principais características e, ainda, quais são as condutas assemelhadas que podem induzir a conclusões equivocadas quanto à ocorrência deste crime e como diferenciá-las satisfatoriamente no contexto da migração internacional.

O tráfico de pessoas, portanto, é definido como:

o recrutamento, o transporte, a transferência, o alojamento ou o acolhimento de pessoas, recorrendo à ameaça ou uso da força ou a outras formas de coação, ao rapto, à fraude, ao engano, ao abuso de autoridade ou à situação de vulnerabilidade ou à entrega ou aceitação de pagamentos

por meio da aplicação de controles mais rigorosos de imigração, muitos atores não-estatais argumentam que o contrário é verdade. Assim, por exemplo, enquanto o ministro das Relações Exteriores italiano disse em uma conferência de imprensa durante a reunião Iniciativa Centro-Europeia em Trieste em novembro de 2001 que 'Reprimir a imigração ilegal é um dos nossos objetivos. Reforçar nossos esforços contra o tráfico humano é essencial na luta pelos direitos humanos fundamentais', a Organização Internacional do Trabalho defende que as políticas migratórias restritivas, na verdade, mercados de combustíveis para o contrabando e o tráfico de migrantes (OIT, 2002)" ibidem. p. 7

20 Promulgados pelos Decretos n. 5.015; 5016 e 5017/2014 da Presidência da República do Brasil. 
ou benefícios para obter o consentimento de uma pessoa que tenha autoridade sobre outra para fins de exploração. A exploração incluirá, no mínimo, a exploração da prostituição de outrem ou outras formas de exploração sexual, o trabalho ou serviços forçados, escravatura ou práticas similares à escravatura, a servidão ou a remoção de órgãos; ${ }^{21}$

A Organização das Nações Unidas - ONU mantém o United Nations Office on Drugs and Crime UNODC, como organismo responsável pelo monitoramento e combate dos crimes transnacionais conforme definidos pela Convenção de Palermo. O UNODC ${ }^{22}$, a partir do normativo acima transcrito, busca os elementos configurados do tráfico de pessoas, a saber: a) o ato (o que é feito) - recrutar, transportar, transferir, alojar ou acolher; b) os meios (como é feito) - por ameaça ou uso da força, ou coerção e abuso contra a vítima e; c) o objetivo (por que é feito) - para fins de exploração, o que inclui questões relativas à prostituição em benefício de outrem, trabalho forçado, escravidão e, por fim, remoção forçada de órgãos ${ }^{23}$.

A importância da elaboração desse conceito normativo se revela a partir da possibilidade efetiva de diferenciação da espécie - condutas criminais no contexto migratório - do gênero migração que, a rigor, não deveria sofrer tratamento sob a ótica criminal. Ainda com olhar voltado para a definição de tráfico de pessoas, é possível compreender outras e diferentes condutas criminosas contra a pessoa migrante. Tais condutas, conquanto possam estar relacionadas, de alguma forma, ao tráfico de pessoas, com ele não se confundem, conforme demonstraremos em continuação.

A primeira realidade que pode gerar alguma compreensão equivocada relativamente ao tráfico de pessoas é a questão da prostituição. Vale destacar que a confusão de conceitos ora analisada ocorre porque, até a elaboração da Convenção de Palermo e seus protocolos adicionais, o

${ }^{21}$ Definição nos termos do Protocolo Adicional à Convenção das Nações Unidas contra o Crime Organizado Transnacional Relativo à Prevenção, Repressão e Punição do Tráfico de Pessoas, em Especial Mulheres e Crianças.

22 O UNODC, por sua vez, mantém programas como a Iniciativa Global da ONU contra o Tráfico de Pessoas (UN-GIFT, da sigla em inglês), que contribui para a inclusão da sociedade civil no debate sobre a questão, trazendo para discussão temas como a vinculação do tráfico de pessoas com vulnerabilidades, inclusive relacionadas às DST/HIV/ AIDS.

23 Oportuna a consulta à página da internet da instituição. Disponível em: <https://www.unodc.org/lpo-brazil/pt/trafico-de-pessoas/index.html>. Acesso em: 7 ago. 2015. tratamento normativo dado por documentos internacionais sempre se referiam, especificamente, à situação das mulheres ${ }^{24}$. É nos Protocolos da Convenção de Palermo que se estende o alcance de sua proteção, utilizando-se, pela primeira vez, da nomenclatura "pessoa".

O importante nesse contexto é estabelecer algumas diferenças fundamentais relativas a três conceitos distintos: a) tráfico de pessoas; b) prostituição e; c) exploração forçada da prostituição. Isto porque, após anos de tratamento da temática da comercialização sexual como, necessariamente, ilegal, o pensamento moderno se modificou para tratar a questão de maneira diferenciada. A Organização das Nações Unidas - ONU, a partir de 1990, aponta para uma tendência de entender a prostituição ou o comércio do sexo como uma forma legítima de trabalho, quando voluntária. ${ }^{25}$

Esta posição atribuída à ONU não é unânime e sofre severas críticas de setores da sociedade relacionados com o estudo da questão da prostituição, tais setores defendem que a prostituição necessariamente consubstancia a exploração e, assim, repudiam a própria concepção de que possa ser uma atividade legitimada normativamente. Contudo, para os fins específicos do presente trabalho, essa controvérsia não será enfrentada com maior profundidade uma vez que o interesse da pesquisa limita-se a demonstrar que se trata de atividade que sempre está

O Acordo para a Repressão do Tráfico de Mulheres Brancas de 1904 (Decreto 5.591/1905); da Convenção Internacional para a Repressão do Tráfico de Mulheres Brancas de 1910 (Decreto 16.572/1924); da Convenção Internacional para a Repressão do Tráfico de Mulheres e de Crianças de 1921 (Decreto 23.812/1934); do Protocolo de Emenda da Convenção para a Repressão do Tráfico de mulheres e de Crianças, de 30 de setembro de 1921, e da Convenção para a Repressão do Tráfico de Mulheres Maiores, de 11 de outubro de 1933 (Decreto 37.176/1955); da Convenção para a Repressão do Tráfico de Pessoas e do Lenocínio e Protocolo Final (Decreto 46.981/1959).

25 Nesse sentido Kamala Kempadoo: "O projeto de pesquisa mundial encomendado pela Relatora Especial da ONU sobre a Violência contra as Mulheres, Rhadika Coomarswamy, em meados da década de 1990, que resultou na sugestão de que a ONU separasse os processos de recrutamento e transporte sob coação do comércio do sexo: isto é, distinguisse conceitualmente tráfico de prostituição. Além disso, a Relatora Especial da ONU definiu a prostituição como forma legítima de trabalho, e o comércio global do sexo foi definido como um lugar, mas não o único, em que ocorre o tráfico." KEMPADOO, Kamala. Shifting the debate on the traffic of womem. 2005. Disponivel em: $<$ http://www.scielo.br/scielo.php?script=sci_arttext\&pi$\mathrm{d}=$ S0104-83332005000200003\#top16>. Acesso em: 7 ago. 2015. 
envolvida em certo grau de risco para a pessoa migrante e, nesse sentido, não há divergência entre as diversas correntes que estudam a questão. Ainda, assim, não nos parece ser possível afirmar que a prática de comercialização sexual, em si mesma considerada, se confunda com o tráfico de pessoas, visto que é admissível, ainda que de difícil realização no contexto prático, o trabalho voluntário nesse ramo de atividade.

Todavia, mesmo entre os defensores da normatização da atividade e dos direitos dos chamados trabalhadores sexuais, sempre com base na pressuposição da voluntariedade, há uma clara percepção do grande risco potencial de exploração da pessoa, especialmente o migrante em situação irregular, tanto que defendem uma rigorosa regulamentação ${ }^{26}$.

Assim, como já afirmamos, o foco de interesse específico da presente argumentação é esse risco que envolve a atividade da prostituição, quando se dá no meio do fenômeno migratório, devido à alta carga de vulnerabilidade que envolve migrantes, especialmente aqueles que não conseguem regularizar sua situação no país de destino. Nesse contexto, muitas vezes, uma realidade que se inicia com consciência e voluntariedade, acaba se tornando um grotesco quadro de exploração. A propósito, destaca-se a análise de Kempadoo e Jyoti Sanghera, que a aponta que, em alguns casos, a comercialização do sexo é considerada pelo pretendente migrante, conscientemente, o único meio para a realização do movimento migratório, bem como para a viabilização e manutenção de sua permanência no país de acolhimento. ${ }^{27}$

Conclui-se, portanto, que a prostituição não se

26 A propósito, citamos Ditmore e Wijers no artigo The Negotiations on de UN Protocolo on Trafficking in Persons - publicado por Nemessis (2003, p. 82) - verbis: "it is imperative to note that sex workers' rights advocates acknowledge that sex work is hard work and that conditions in the sex industry vary from relatively good to extremely exploitative and abusive, the latter often facilitated by the exclusion of (migrant) sex workers from the rights and legal protection granted to others as citizens and workers.11 Consequently, they seek to correct these abuses by improving conditions and affording legal recognition to the sex industry, in contrast to the 'abolitionists' Who seek to make the sex industry more illegal than it currently is and to prosecute and punish men involved as clients or otherwise." Disponível em: <http://www.bayswan.org/traffick/NEMESIS_Ditmore.PDF $>$. Acesso em: 10 ago. 2015.

27 KEMPADOO, Kamala; SANGHERA, Jyoti; PATTANAIK, Bandana. Trafficking and prostitution reconsidered: new perspectives on migration, sex work, and human rights. 2. ed. London: Paradigm Publishers, 2005. p. 8. confunde com o tráfico de pessoas, conquanto seja um dentre outros fatores que podem contribuir para sua ocorrência. Por outro lado, é também possível verificar que o contexto de irregularidade do migrante - especialmente, mas não exclusivamente, as mulheres - coloca-o em situação de grande vulnerabilidade, tendente a produzir situações de exploração a partir da sua condição de ilegalidade no país de acolhimento. Tais circunstâncias parecem apontar para o ponto básico defendido na presente investigação, qual seja, a defesa de uma legislação migratória que possibilite, ou até mesmo facilite, a regularização da situação do migrante, retirando-o, assim, desta fronteira de vulnerabilidade exacerbada.

De acordo com a realidade fática que causa alguma perplexidade na definição do tráfico de pessoas, é a questão do contrabando de migrantes, figura criminal que, a exemplo da exploração sexual, guarda relação com tráfico sem, contudo, se confundir com ele. Segundo o UNODC o "contrabando de migrantes é um crime que envolve a obtenção de benefício financeiro ou material pela entrada ilegal de uma pessoa num Estado no qual essa pessoa não seja natural ou residente." ${ }^{28}$ A mesma entidade ainda explica que a diferença fundamental entre o contrabando de migrantes e o tráfico de pessoas se dá no consentimento e conhecimento da vítima, no caso do contrabando, e na irrelevância desse consentimento, na hipótese do tráfico, para concluir que as vitimas do tráfico são afetadas mais severamente e carecem de maior proteção.

Não há como se confundir as duas figuras delituosas, uma vez que o tráfico de pessoas se caracteriza pela coação do traficante sobre a vítima, enquanto o contrabando firma-se na mutualidade de interesses daquele que deseja encontrar uma porta de entrada para um novo país e os que aproveitam esta circunstância para auferir alguma vantagem pecuniária. Oportuna, ainda, a análise de Annie Gallagher, Conselheira do Alto Comissariado da ONU para Direitos Humanos (OHCHR), a propósito do contrabando, ao verificar que a relação que se dá entre contrabandista e migrante dura apenas até o momento de entrada deste no país escolhido e, a partir de então, essa

28 Observamos que o conceito normativo de contrabando de migrantes encontra-se no Protocolo Adicional à Convenção das Nações Unidas contra o Crime Organizado Transnacional, relativo ao Combate ao Tráfico de Migrantes por Via Terrestre, Marítima e Aérea, já mencionado neste trabalho. Disponível em: <https://www.unodc.org/lpo-brazil/ $\mathrm{pt} /$ trafico-de-pessoas/index.html $>$. Acesso em: 11 ago. 2015. 
relação se encerra, restando ao migrante viabilizar, sozinho, sua permanência no local ${ }^{29}$.

Ainda assim, a mencionada conselheira continua sua argumentação para concluir que o elo comum entre todas essas formas criminais tratadas pelos dois Protocolos adicionais da Convenção de Palermo é mesmo a vulnerabilidade que a situação de ilegalidade gera para a pessoa do migrante. É sempre importante destacar que o criminoso não é o migrante, mas aquele que obtém lucro com a sua entrada ilegal no país de destino ou o explora das variadas formas previstas nos mencionados protocolos.

É possível vislumbrar outras situações de vulnerabilidade dos migrantes não documentados ou irregulares, as quais podem ser deduzidas do conceito de tráfico de pessoas, nos termos do Protocolo Adicional à Convenção das Nações Unidas contra o Crime Organizado Transnacional Relativo à Prevenção, Repressão e Punição do Tráfico de Pessoas, em Especial Mulheres e Crianças, quais sejam, o trabalho ou serviços forçados, escravatura ou práticas similares à escravatura, além da servidão, todos na linha da exploração de força de trabalho ${ }^{30}$ e a remoção forçada de órgãos, triste fenômeno de crescente incidência no mundo globalizado. ${ }^{31}$

Vê-se, por toda linha de argumentação que buscamos desenvolver até aqui, que há uma centralidade no problema da não regularização da pessoa migrante, que faz nascer o contexto favorável para que se tornem víti-

29 GALLAGHER, Anne. Trafficking, smuggling and human rights: tricks and treaties. Forced Migration Review, Oxoford, UK, n. 12, p. 25-28, 2002. Citamos o original: "Smuggled migrants are moved illegally for profit: they are partners, however unequal, in a commercial transaction. All going well, their relationship with the smuggler ends at the destination country and they may even manage to survive the ordeal with only financial damage." Disponível em: <http://www.fmreview.org/FMRpdfs/FMR12/ fmr12.9.pdf $>$. Acesso em: 11 ago. 2015.

30 A propósito das definições mencionadas, consultar: Aliança global contra trabalho forçado - Relatório Global do Seguimento da Declaração da OIT sobre Princípios e Direitos Fundamentais no Trabalho 2005. Disponível em: <http:// reporterbrasil.org.br/documentos/relatorio_global2005. pdf>. Acesso: 11 ago. 2015.

31 Para um primeiro contato com este árduo tema do tráfico de órgãos, recomendamos a leitura de entrevista com Nancy Scheper-Hughes, diretora do Organs Watch e professora de antropologia da Universidade da Califórnia, Berkeley, publicada na pela Folha de São Paulo, 15-092014. Disponível em: <http://www1.folha.uol.com.br/cotidiano/2014/09/1509539-para-especialista-trafico-de-pessoas-para-obter-orgaos-e-crime-protegido.shtml>. Acesso em: 11 ago. 2015. mas da exploração de sua força de trabalho (quando não lhes custam a própria vida) seja qual for o ramo em que se aventure, desde as controversas atividades sexuais, até o auxílio em tarefas domésticas nas residências dos habitantes locais. $\mathrm{O}$ clímax dessa vulnerabilidade à exploração se dá na figura do tráfico de pessoas, conforme vimos em sua conceituação acima transcrita, que, ao cabo, funde-se com todas as formas de exploração aqui delineadas, cada uma delas espécie distorcida do fenômeno migração.

Nunca é demasiado frisar a gravidade dessa realidade do tráfico de pessoas, na medida em que se consubstancia profunda agressão aos direitos humanos, em especial, pela sua tendência à perenidade com a continuidade da exploração do outro com base em sua condição vulnerável no contexto migratório. Há no Brasil algumas iniciativas governamentais que buscam delinear o problema do tráfico de pessoas e da exploração no ambiente dos trabalhos forçados ou das práticas similares à escravidão que merecem referência, pois apontam exemplos concretos das relações entre as condutas criminosas ora examinadas e à situação dos imigrantes.

A propósito e a título exemplificativo, destacamos o trabalho realizado pela Secretaria da Justiça e da Defesa da Cidadania do Estado de São Paulo ${ }^{32}$, que busca traçar um mapeamento sobre o tráfico de pessoas naquele estado. Interessante notar que, dentro das diretrizes da pesquisa, o leitor é noticiado sobre o arcabouço da Política Nacional de Enfrentamento ao Tráfico de Pessoas ${ }^{33}$, inspirada nas recentes normatizações oriundas da Convenção de Palermo, já mencionada no presente trabalho de pesquisa, bem como, na mesma linha, os projetos para erradicação do trabalho escravo ${ }^{34}$. Com base na análise

Tráfico de Pessoas e Trabalho Escravo no Estado de São Paulo. Análise dos procedimentos judiciais e extrajudiciais do Ministério Público do Trabalho e Ministério Público Federal. Disponível em: <http://www.justica.sp.gov.br/ StaticFiles/SJDC/ArquivosComuns/ProgramasProjetos/ NETP/Pesquisa\%20sobre\%20Trabalho\%20Escravo\%20 e\%20Tr\%C3\%A1fico\%20de\%20Pessoas.\%20Governo\%20 do\%20Estado\%20de\%20S\%C3\%A3o\%20Paulo.pdf>. Acesso em: 14 ago.2015.

33 Instituída pelos: Decreto $\mathrm{n}^{\circ} 5.948$, de 26 de outubro de 2006, com princípios, diretrizes e ações que devem guiar a política pública sobre o tema, em todas as esferas de governo. Decreto $n^{\circ} 6.347$, de 8 de janeiro de 2008 (I Plano Nacional de Enfrentamento ao Tráfico de Pessoas (PNETP). Decreto $\mathrm{n}^{\circ} 7.901$ de 4 de janeiro de 2013, que implementa o II PNETP com a instituição do Comitê Nacional de Enfrentamento ao Tráfico de Pessoas (CONATRAP)

34 Decreto n. 31, de julho de 2003 (I Plano Nacional para Erradicação do Trabalho Escravo) e criação da Comissão Na- 
de procedimentos judiciais e extrajudiciais conduzidos pelo Ministério Público do Trabalho e pelo Ministério Público Federal, no âmbito do Estado de São Paulo, foram delineadas as ocorrências de tráfico de pessoas e trabalho escravo naquela região.

Os resultados revelam que muitas dessas situações têm estreita relação com a situação de migrantes, especialmente oriundos da América do Sul e particularmente da Bolívia. Dado bastante expressivo dessa pesquisa ora analisada é constatação de que, nos procedimentos instaurados pelo Ministério Público do Trabalho, o percentual de vítimas de exploração do trabalho escravo ou similar à escravidão revela que $62 \%$ das vítimas são imigrantes internacionais, percentual expressivo quando comparado com as vítimas nacionais, 38\%. O maior número de ocorrências se dá entre as vítimas bolivianas que superam, inclusive, sozinhas, as vítimas brasileiras. Os percentuais divulgados são de 52\% de bolivianos; $38 \%$ para brasileiros; 7\% para Haitianos; 3\% para paraguaios e $0.5 \%$ para os chilenos ${ }^{35}$.

Destacamos, das conclusões do relatório, a percepção de que o ramo têxtil do Estado de São Paulo é o que mais absorve migrantes internacionais impondo condições de trabalho altamente desfavoráveis a ponto de configurar a exploração em nível similar à escravidão. As conclusões da pesquisa, nesse particular, apontam que se trata de opção de trabalho somente aceita pelos migrantes em face da propalada vulnerabilidade de sua situação, uma vez que as condições degradantes não são capazes de captar o interesse dos brasileiros. ${ }^{36}$ Assim, após concluir pela maior aptidão dos migrantes para submeterem-se às condições precárias e exploradoras dos empregos oferecidos, a pesquisa aponta que: "a política pública para seu enfrentamento parece dever ser pensada em termos de acolhida adequada desses migrantes e in-

cional de Erradicação do Trabalho Escravo (CONTRAE) que, em 2008, realizou o primeiro plano e elaborou sua segunda versão.

35 Vide Gráfico 30, p. 55 do relatório ora analisado (cf. nota 81)

36 "Diferentemente de outros ramos de exploração, aqui foram identificadas vítimas saídas da Bolívia e do Paraguai. Ao que parece, as oficinas de costura oferecem oportunidades de trabalho em condições que não interessam aos brasileiros, justamente devido à precarização, o que abre espaço para esses migrantes, cujo objetivo central pode não ser o de criar raízes no país, mas sim gerar renda e enviar aos seus familiares, mesmo que para isso tenham que se sujeitar a abusos." p. 71 do mesmo relatório (cf. nota 81) centivo a regularização e integração de seus negócios no Estado." ${ }^{37}$

Uma análise mais abrangente da mesma temática pode ser realizada a partir do Relatório Global do Seguimento da Declaração da OIT sobre Princípios e Direitos Fundamentais no Trabalho - Uma Aliança Global Contra o Trabalho Forçado da Organização Internacional do Trabalho - Brasil que, em seu Capítulo 5, cuida da temática do Trabalho Forçado, migração e tráfico de pessoas ${ }^{38}$.

O mencionado Capítulo 5 do referido relatório apresenta um extenso estudo, realizado em diferentes países, sobre a questão da exploração do trabalho forçado e sua relação com a migração. Considerando países de origem como a Albânia, a República da Moldávia, a Romênia , o Tajiquistão e a Ucrânia e, os países de origem, dentre os quais se destacam, França, Alemanha, Hungria, Japão, Federação Russa e o Reino Unido, catalogaram-se 300 casos de trabalho forçado, abordando, entre as principais questões, o perfil das vítimas; sistemas de recrutamento; o uso de documentos de viagem, autorizações de trabalho, formas de coerção experimentadas pelas vítimas e saída da situação de trabalho forçado. A pesquisa apontou como causa da exploração do migrante em trabalhos forçados a falta de informações e dados sobre ofertas de emprego, a dependência de intermediários e o acesso restrito a canais legais de migração ${ }^{39}$.

Para concluir o presente tópico, faz-se necessário mencionar, ainda, estudo realizado pelo Ministério da

37 MERÇON, Marines. Imigrantes bolivianos no trabalho escravo contemporâneo: análise do caso Zara a partir das RPGs. Revista do CEDS, São Luís - MA, n. 2, v. 1, p. 1-23, bimestral, 2015. Disponível em: <http://www.undb.edu. br/publicacoes/arquivos/revceds_n_2_imigrantes_bolivianos_e_trabalho_escravo_contemporaneo_caso_zara_marineis_mercon.pdf>. Acesso em: 14 ago. 2015.

38 Disponível em: <http://reporterbrasil.org.br/documentos/ relatorio_global2005.pdf>. Acesso em: 14 ago. 2015.

39 Nesse sentido "[...] embora possa ser útil abrigar o trabalho forçado sob o guarda-chuva de leis e políticas antitráfico, a realidade é mais complexa. É comum migrantes entrarem nos países de destino por sua própria vontade, talvez com a ajuda de amigos ou de membros da família que ali já se encontram. Podem, entretanto, estar mais vulneráveis à exploração de trabalho forçado, sobretudo quando se encontram em situação irregular e vivem sob contínua ameaça de denúncia às autoridades e de eventual deportação. Assim, o trabalho forçado tem menos probabilidade de derivar diretamente de um processo de recrutamento abusivo e enganoso no país de origem do que de um processo de entrada clandestina num país. De fato muitas vezes é difícil distinguir, na prática, entre trabalhadores que caíram em trabalho forçado como resultado de tráfico e da imigração clandestina “ Relatório Global OIT, p. 52. 
Justiça em parceria com o UNODC ${ }^{40}$. O trabalho tem relevância para a presente pesquisa, na medida em que busca determinar quantitativos de brasileiros que, de algum modo, tornaram-se vítimas de tráfico em suas mais diversas formas e para suas diferentes finalidades, em países receptores da emigração do Brasil.

O estudo aponta que, entre os anos de 2005 e 2011, foram identificados 475 brasileiros, homens e mulheres, vítimas do tráfico: 337 para fins de exploração sexual e 135, para fins de trabalho escravo, além de 03 cuja finalidade não pode ser identificada claramente, em um universo de 18 diferentes países, dentre os quais, a maior incidência foi o Suriname, com 133 vítimas, seguido de Suíça, com 127; Espanha, com 104 e Holanda, com 71 $\operatorname{casos}^{41}$. É a outra face do tratamento inadequado ao migrante, fenômeno que atinge de maneira indiscriminada os atores humanos dos fluxos migratórios, revelando que, por vezes, seremos, enquanto Estado Brasileiro, maus receptores e, na outra ponta, nossos concidadãos serão as vítimas de outros Estados, igualmente inaptos ao exercício adequado da hospitalidade migratória.

A vulnerabilidade do migrante em situação irregular parece ser, portanto, uma característica universal implementadora das condições para o tráfico de pessoas, em suas mais variadas formas de exploração. Tal constatação aponta, mais uma vez, para a demonstração da viabilidade da hipótese proposta na presente investigação, com o sentido de urgência da implementação de marco regulatório mais favorável à regularização da situação migratória, possibilitando, assim, no âmbito do nosso país, o modelo e exemplo para a esfera internacional, e quem sabe o constrangimento ao tratamento igualitário e à reciprocidade para os nossos emigrantes em outras nações.

\subsubsection{Ausência de relação direta do terrorismo com imigrantes}

Como mencionado no início do presente artigo, os eventos terroristas de 11 de setembro de 2001 geraram uma forte reação das nações afetadas, em especial os Estados Unidos da América, mas obviamente no contexto da Europa também, com relevantes reflexos sobre a própria noção de migração. No início do ano de 2015, o ata-

40 Relatório Nacional Sobre Tráfico de Pessoas: Consolidação dos Dados de 2005 a 2011. Disponível em: <http://www.unodc.org/documents/lpo-brazil/noticias/2013/04/2013-04-08_Publicacao_diagnostico_ETP. pdf $>$. Acesso em: 14 ago. 2015. que à redação do jornal francês Charlie Hebdo e os recentes atentados à cidade de Paris, no final do ano de 2015, causaram nova onda de endurecimento no tratamento da questão migratória na França, seguindo o mesmo padrão da prévia ocorrência terrorista americana.

No caso dos Estados Unidos, foi evidente a reação aos mencionados ataques terroristas, com a elaboração de política restritiva e de rigoroso controle da imigração para o país, ainda sob o comando do Presidente George W. Bush.

John Tirman, do Center for International Studies, do Massachusetts Institute of Technology - MIT, em artigo publicado no ano de $2006^{42}$, analisando as consequências que os ataques do 11 de Setembro geraram sobre a política migratória norte-americana, explica que, de fato, houve percepção mudança do enfoque com um exagerado alarme sobre a segurança das fronteiras americanas. Segundo o autor, o foco imediato deu-se sobre os imigrantes árabes e muçulmanos, porém, o problema do tratamento repressivo também passou a afetar outras comunidades, nitidamente os Latinos, com ênfase na situação dos Mexicanos. ${ }^{43}$

A conclusão, não obstante, a que chega o autor, é no sentido de que se trata de abordagem exagerada que, tão somente, serviu para elevar o nível de intimidação e agressão a direitos fundamentais dos imigrantes, em especial a comunidade de Latinos. Ao final de seu artigo, argumenta, na mesma linha de intelecção, que vem sendo defendida no presente trabalho, que o tratamento crimi-

42 TIRMAN, John. Immigration and insecurity: post-9/11 fear in the United States. Massachusetts - USA: MIT Center for International Studies Audit of the Conventional Wisdom. p. 6-9, jun, 2006. Disponível em: <http://web. mit.edu/cis/pdf/Audit_Tirman_Immigration_6.06.pdf > Acesso em: 14 out. 2015

43 A mudança na abordagem migratória, que se move de questões de ordem social, previdenciária ou de emprego para a órbita da segurança é assim descrita pelo citado articulista, que destaca, inclusive, o implemento de novo contexto legal formulado pelo Congresso Americano. “ Migration has long had security implications, but mostly linked to "social" security_-jobs, welfare etc. Today it is the threat of terrorism that frames debate. The fear-thus far, unfounded-that al Qaeda will sneak across the "unguarded" 2,000-mile border accounts for the urgency. In fact, the House bill is called the Border Protection, Antiterrorism, and Illegal Immigration Control Act of 2005. John Tirman. "Immigration and Insecurity: Post-9/11 Fear in the United States.” MIT Center for International Studies Audit of the Conventional Wisdom, 06-09 (June 2006) p. 2. Disponível em: <http://web.mit.edu/cis/pdf/Audit_Tirman_Immigration_6.06.pdf $>$. Acesso em: 14 out. 2015. 
nal aos imigrantes não autorizados, ou irregulares, não trás benefícios reais e não melhora a segurança do país contra atos terroristas, até porque atentados deste tipo não estão necessariamente vinculados à imigração irregular, ou não autorizada, mas, comumente, estão mais relacionados com pessoas portadoras de autorizações de entrada, sejam vistos de turismo ou estudo, ou mesmo permissão temporária de trabalho.

Esta, aliás, é a exata abordagem de Daniel Griswold $^{44}$ ao comentar o papel positivo dos imigrantes sobre a economia, sociedade e cultura americana, enfatizando que o fenômeno migratório sempre foi um marco daquela nação. Relativamente à questão terrorista o articulista argumenta que o problema das ações terroristas não se relaciona à imigração irregular, mas, ao contrário, está vinculado aos vistos concedidos para turismo ou estudo.

De fato, pode-se vislumbrar, também, no ambiente Europeu, preocupações similares relacionadas com a própria existência de seu bloco regional, que se vincula a uma crescente discussão acerca do significado dos fluxos migratórios, com uma nítida tendência ao tratamento da questão sob a ótica da segurança. A propósito, o estudo de Jef Huysman que examina a questão para descrever um processo institucional e político, no âmbito do bloco europeu, que constrói a passagem das conotações de segurança associadas ao terrorismo e outros crimes, para as políticas migratórias.

Assim, um dos interesses do referido estudioso é a tentativa de compreensão do processo que levou as migrações a se transformarem em assunto de segurança na Europa. Para o autor, houve uma perspectiva de que seria necessário conectar a questão do controle das fronteiras do bloco ao tema da expansão do mercado interno e da garantia da estabilidade econômica e o consequente bem-estar social de seus habitantes nativos ${ }^{45}$.

${ }_{44}$ GRISWOLD, Daniel. Immigrants have enriched American culture and enhanced our influence in the world. 2002. Cato Institute. Disponível em: <http://www.cato.org/publications/commentary/immigrants-have-enriched-american-culture-enhanced-our-influence-world $>$. Acesso em: 14 out. 2015.

45 "To make the issues of border control a security question, however, teh internal market had to be connected to an internal security problematique. A key element in this process was the identification of a particular side-effect of the creation of the internal market. One expected that the market would not only improve free movement of law-abiding agents, but would also facilitate illegal and criminal activities by terrorists, international criminal organizations, asylum-seekers and immigrants. The institutionalization
A conclusão do pesquisador ora analisado, neste seu artigo produzido no final do ano de 2000, já apontava para o enorme risco de que este tipo de política de deliberada confusão entre as questões migratórias e os problemas de segurança, em especial, a questão do terrorismo, no âmbito da consolidação do sistema regional europeu, teria como consequência o incremento das posições xenofóbicas que nutririam um olhar desconfiado da sociedade europeia para com os imigrantes, vinculando-os facilmente aos problemas de criminalidade, instabilidade social doméstica, fraudes e crimes transnacionais. Obviamente, todo esse arcabouço de concepções preconceituosas dificultaria bastante a percepção de Huysmans, a respeito da inclusão dos imigrantes na comunidade europeia.

Nessa mesma linha de intelecção, a junção das duas temáticas - crime e mobilidade internacional - ganha contornos de centralidade na negociação internacional capitaneada pela ONU para elaboração da Convenção das Nações Unidas contra o Crime Organizado Transnacional - já mencionada no presente trabalho, conhecida como a Convenção de Palermo e seus protocolos adicionais sobre o tráfico de pessoas - levando, inclusive à escolha de uma estrutura criminal para o tratamento das questões relacionadas à mobilidade humana. ${ }^{46}$

Interessante ainda destacar que, em relação ao exame dos "Tavaux Préparatoirs" ${ }^{47}$ da Convenção de $\mathrm{Pa}$ lermo, pode-se concluir a existência de um patente desequilíbrio entre as discussões de medidas de proteção e assistência às vítimas de tráfico de pessoas e aquelas destinadas ao estabelecimento de mecanismos de cooperação entre as autoridades estatais para perseguição e punição aos criminosos com evidente delineação da prioridade,

of police and customs co-operation, and de discourses articulating this particular side-effect, produced a security continuum connecting border control, terrorism, international crime and migration." HUYSMANS, Jef. Journal of Common Market Studies, Oxford - UK, v. 38, n. 5, p. 751777, dez-2000. Disponível em: <http://onlinelibrary.wiley. com/doi/10.1111/1468-5965.00263/pdf >. Acesso em: 13 out. 2015.

46 DIAS, Guilherme Mansur. Migração e crime: desconstrução das políticas de segurança e tráfico de pessoas. 2014. Tese (Doutorado) - Universidade Estadual de Campinas, Campinas, SP, 2014. p. 45.

47 Atas que reúnem as colocações e proposições das delegações e representantes que participam de um Convenção Internacional. DIAS, Guilherme Mansur. Migração e crime: desconstrução das políticas de segurança e tráfico de pessoas. 2014. Tese (Doutorado) - Universidade Estadual de Campinas, Campinas, SP, 2014. p. 55. 
ou seja, a repressão, em detrimento da assistência as vítimas. $^{48}$

Em conclusão, podemos afirmar que as abordagens americana e europeia se repetem numa perspectiva global - temor compreensível ante a presença de organizações ultraextremistas como o denominado Estado Islâmico, contudo, ainda assim, infundado para a esmagadora maioria dos casos de imigração.

O que se vê na análise da questão migratória é uma crescente vinculação do fenômeno com o terrorismo, relação esta que, repetimos, nos parece muitas vezes tratada de forma exacerbada. Há um reforço bastante acentuado, no âmbito dos Estados tradicionalmente receptores, de uma visão que vincula o terrorismo com os fluxos internacionais de pessoas, com a consequente transferência do tratamento da questão migratória para o ambiente da segurança, em detrimento de uma abordagem do fenômeno sem a ênfase criminal.

Continua sendo necessária uma compreensão mais profunda do problema migratório mundial, com a separação e diferenciação das questões relativas ao fluxo da migração e o tratamento dado ao risco do terrorismo, para a segurança do país receptor.

\section{Instrumentos do direito administrativo Glo- bal para o tratamento da problemática mi- gratória}

A problemática dos fluxos migratórios deve ser compreendida dentro da perspectiva da globalização.

48 "Se a questão do crime organizado transnacional preocupava - como continua a preocupar - uma série de atores envolvidos em discussões sérias e necessárias sobre o assunto, sua vinculação à questão da mobilidade humana não deve ser desconectada de preocupações e contextos regionais específicos. Máfia, crime organizado e corrupção são assuntos graves, que impactam diferentes paragens e que precisam ser debatidos de maneira qualificada. Já o transbordamento de uma linguagem criminal em direção a assuntos afetos à mobilidade humana - e o decorrente tratamento da temática migratória em termos de segurança - longe de jogar luz a essas discussões, parecem servir a interesses de Estados e instituições preocupados em restringir o deslocamento e mobilidade de determinados grupos e indivíduos. Desse modo, o que a vinculação entre migração e segurança acaba fazendo é, ao contrário, desviar o foco de assuntos mais sérios relacionados tanto à questão do crime organizado quanto à questão mais abrangente da segurança internacional.”. DIAS, Guilherme Mansur. Migração e crime: desconstrução das políticas de segurança e tráfico de pessoas. 2014. Tese (Doutorado) - Universidade Estadual de Campinas, Campinas, SP, 2014. p. 55.
Afinal, este é um fenômeno que ultrapassa fronteiras, afetando os Estados como um todo. Globalização pode ser definida como "o conjunto de transformações econômicas, tecnológicas, políticas e sociológicas que afetaram as sociedades, as culturas mundiais e os Estados nacionais ao final do segundo milênio." ${ }^{49}$

Não é objetivo deste trabalho apresentar todas as discussões teóricas sobre a globalização. Tão somente nos referimos ao fenômeno para concluir pela sua efetiva existência, reconhecendo as transformações sociais, políticas, tecnológicas e econômicas que, ocorridas no panorama internacional, especialmente nas duas últimas décadas do século passado, lhe deram gênese.

É a partir dessa globalização, por sua vez, que se pode verificar a criação de um ambiente adequado à formação de um novo mecanismo metodológico de tratamento das questões vinculadas ao Direito e à Administração. Essa abordagem metodológica é que designa o Direito Administrativo Global (DAG). ${ }^{50}$

Algumas características que condicionam a formação do DAG a partir de um espaço administrativo global, são: a) o declínio da estrita dicotomia entre o direito interno e o internacional; b) realização de funções administrativas a partir de diversas interações complexas entre representantes dos governos e instituições não governamentais de diferentes níveis e modelos e c) preocupação com a criação de mecanismos de controle - designada referencialmente como accountability - capaz de aferir a legitimidade destas interações entre o público e o privado; o governamental e o não governamental ou o direito interno e o internacional. ${ }^{51}$

O tratamento dos fluxos migratórios deve ser considerado a partir dessa nova metodologia de análise que evidencia, de modo mais direto, a importância da relação

49 HEILMANN, Maria de Jesus Rodrigues Araújo. Globalização e o novo direito administrativo. Curitiba: Juruá, 2010.

50 Direito administrativo global pode ser definido como: “[...] o ramo que abraça as estruturas, os procedimentos e estándares normativos (princípios) para a tomada de decisões reguladoras incluindo os princípios da transparência, da participação e revisão, razoabilidade e da proporcionalidade e os mecanismos de governo-regulação para implementação destes estándares, que são aplicáveis aos corpos administrativos intergovernamentais formais e informais." HEILMANN, Maria de Jesus Rodrigues Araújo. Globalização e o novo direito administrativo. Curitiba: Juruá, 2010. p. 174.

51 KRISCH, Nico; KINGSBURY, Benedict. Introdução: governança global e direito administrativo global. $R D A-R e-$ vista de Direito Administrativo, Rio de Janeiro, v. 261, p. 1332, 2012. p. 15. 
de setores privados juntamente ao Estado, na esperança de se alcançar uma efetividade maior na implementação de instrumentos de controle.

O DAG parte da noção de governança global operada por mecanismos de regulação que se dão nos diversos espaços nacionais, transnacionais e internacionais, de forma a gerar uma atividade reguladora transgovernamental. Tem-se, nessa perspectiva, o acolhimento internacional de diversos padrões regulatórios que, na medida em que acatados por diversos países, cria o ambiente propício para a formação de uma dimensão global da atuação administrativa. Ao conjunto de fatores descritos acima é que s denominam de espaço administrativo global.

Em relação a essa concepção de espaço administrativo global, é possível extrair as linhas básicas da doutrina norte-americana do DAG, quais sejam: a) a emergência mensurável de mecanismos de DAG que visam desenvolver uma maior responsabilidade na tomada de decisões e; b) o estudo descritivo de tais mecanismos reguladores globais.

Os exemplos concretos e demarcadores da efetiva ocorrência desse novo sistema de exame da questão regulatória nas relações internacionais podem ser colhidos em distintas e exponenciais áreas da vida econômica ou social, em que é possível verificar o tipo de regulação característica do DAG. São elas: a) segurança internacional; b) condições de desenvolvimento e ajuda financeira aos países subdesenvolvidos ou em vias de desenvolvimento; c) proteção ambiental; d) atividades bancárias e regulação financeira; e) aplicação da lei no espaço nacional ou do direito administrativo doméstico; f) telecomunicações, comércio, produtos e serviços; g) propriedade intelectual; h) standards trabalhistas; e, por derradeiro, a temática mais próxima da abordagem proposta no presente artigo, i) movimentos transfronteiriços de populações, incluindo-se os refugiados.

A dimensão regulatória para as áreas acima mencionadas, cada vez mais, escapa do âmbito meramente interno de cada país, ou do espaço doméstico do Estado nacional, para ganharem um status de normatização acolhida no domínio internacional, sendo reconhecidas como regulação transnacional. O que determina o potencial globalizante dessa regulação, em larga medida, é sua origem, ou seja, que tipo de organismo ou instituição que atua para criação da normatização, que normalmente se dá em relevante contexto intersubjetivo, com sujeitos de várias naturezas distintas, porém, interligadas, a saber, indivíduos representantes de empresas multinacionais; Estados e seus agentes públicos e organizações não governamentais com interesses globais ou regionalizados.

Na metodologia do DAG, são destacados novos sujeitos para além das instituições públicas tradicionalmente reconhecidas como fontes reguladoras das relações jurídicas, com destaque para entidades de caráter híbrido, ou meramente privado, que, também, acabam por determinar padronização regulatória de âmbito global. Exemplificamos com entidades de envergadura global, chamadas organizações internacionais mundiais (OIM), como a Organização Mundial do Comércio (OMC); a Agência Mundial Antidoping (WADA) ou o Banco Mundial e o Fundo Monetário Internacional (FMI).

Há referências doutrinárias, também, às chamadas redes informais de autoridades, cujo exemplo trazido é o Comitê de Supervisão Bancária da Basilea, cuja atuação tem por característica a cooperação entre entidades de aparatos diferenciados, mas não a estrutura fechada da organização jurídica dos Estados soberanos, regendo-se por deliberações de outros organismos internacionais.

Da atuação dessas diversas instâncias econômicas e sociais internacionais, é possível delimitar-se cinco fontes de DAG: 1) Administração formada por organizações internacionais formais (mediante tratados-base dos organismos internacionais); 2) As redes intergovernamentais informais de funcionários da regulação doméstica oficial; 3) As autoridades domésticas que executam no âmbito interno dos governos a regulação global do regime dos tratados, dos acordos de reconhecimento mútuo ou estándares cooperativos; 4) A Administração por via de acordos intergovernamentais emanados dos novos atores dos regimes transnacionais híbridos (público-privado); 5) A Administração de instituições privadas com funções reguladoras (os atores puramente privados). ${ }^{52}$

O que temos, por conseguinte, para a construção de uma conceituação do DAG, é a percepção dos estudiosos da área de que a realidade das relações, quer entre pessoas, quer entre instituições, no contexto internacional, atingiu tal grau de integração e complexidade e tal amplitude de trocas e intercâmbios a partir do fenômeno da globalização, que já não é possível responder a todas as demandas associadas a esta realidade, sem que se conceba uma nova e amplificada perspectiva de exame e normatização destas

2 HEILMANN, Maria de Jesus Rodrigues Araújo. Globalização e o novo direito administrativo. Curitiba: Juruá, 2010. p. 173. 
relações jurídicas internacionais. Nessa medida, a observação empírica aponta para a formação de um ambiente regulatório que extrapola as concepções tradicionais de Direito Administrativo e do Direito Internacional.

Interessante notar que algumas características do DAG o aproximam, sob determinado ângulo de exame, dos dois ramos do Direito acima mencionados, contudo, com eles não se confunde. Por um lado, muito da regulação administrativa necessita do amparo ou suporte da estrutura burocrática interna dos governos locais, ou seja, depende do ambiente jurídico do Direito Administrativo. De outra banda, o arcabouço normativo igualmente requer um alicerce de reconhecimento mútuo entre os entes nacionais envolvidos e interrelacionados pelos interesses globalizados, seara do Direito Internacional clássico. Nessa linha de intelecção, percebe-se que essas citadas esferas tradicionais já não conseguem responder efetivamente à enorme dimensão das relações globalizadas.

No caso do tratamento da problemática dos fluxos migratórios, podemos partir da vertente alemã do DAG que destaca quatro formas de relações administrativas internacionais, quais sejam: a) a cooperação bilateral; b) fontes organizativas regionais; c) formas organizativas de alcance mundial e d) redes informais de autoridades. ${ }^{53}$ De modo mais específico, vale destacar os dois últimos elementos, ou seja, as redes informais de autoridades e as formas organizativas de alcance mundial, como atores do panorama do Direito Administrativo Global com grande possibilidade de influenciar positivamente no contexto de crise migratória. Novos atores transnacionais têm modificado e minorado o monopólio da atuação do Estado que, por sua vez, já não consegue responder efetivamente a todas as demandas que a nova ordem internacional, os avanços tecnológicos, os fluxos migratórios e as comunicações em tempo real produzem.

Em resumo elucidativo da questão, podemos destacar o pensamento de Tomassini ${ }^{54}$, que aponta as características de uma redefinição renovadora dos papéis dos atores não-estatais nas relações internacionais hodiernas.

53 SCHMIDT, Assmann. E. La Ciencia del derecho administrativo ante el reto de la internacionalización de las relaciones administrativas. Revista de Administrción Pública - RAP, Madrid, n. 171, p. 4-11, set./dez. 2006.

54 TOMASSINI, L. El proceso de trasnacionalización y las relaciones externas de América Latina. Buenos Aires: Grupo Editor Latinoamericano, 1984. TOMASSINI, L. El Trasnacionalización y desarrollonacional en América Latina. Buenos Aires: Grupo Editor Latinoamericano, 1984.
Tais relações, na percepção do citado autor, apresentam: a) grande diversificação de centros de poder, cuja atuação deixa de ser pensada em função do Estado para incorporar a sociedade civil organizada; b) fazem surgir uma agenda de discussões internacionais ampliada e menos hierarquizada, com uma consequente estrutura de definição menos centralizada e, c) apresentam um modelo de gestão dos novos problemas internacionais por múltiplos agentes, distintos do Estado.

Com efeito, o papel desempenhado por determinadas organizações não governamentais apela para a noção de influência em contraposição à imposição do poder, característico da atuação clássica estatal. A propósito, destacamos a diferenciação entre estas duas possíveis formas de modificação do contexto internacional, a saber: o uso do poder e o convencimento pela influência ${ }^{55}$.

A diferença básica entre as duas formas de atuação seria que os atores estatais no plano internacional servem-se de dois meios de atuação: a) os meios violentos (coerção) e os meios não-violentos (consenso), o primeiro relacionado ao poderio bélico do agente estatal e o segundo à sua capacidade diplomática e de produzir boa regulamentação legal. Já aos atores não estatais, como as organizações não governamentais, restaria, tão somente, o poder de persuasão, por meio das ideias que defendem. Citamos, por oportuno, o seguinte trecho de suas conclusões quanto à ideia de influência:

dessa forma, a existência da coação, condição necessária embora não suficiente do poder político, representa a diferença entre poder e influência: um ator tem poder de mando, em última instância, na medida em que controla a coerção física; quando carece desta, mas se vale de meios consensuais para conseguir o objetivo de encontrar obediência nas vontades alheias, tem influência. Parodiando Maquiavel, poder-se-ia expressar que só resta aos modernos profetas sem armas, ao estilo das ONGs, fundamentalmente, o expediente da influência. Assim, a especificidade da influência é equivalente ao que Weber chamou de ação politicamente orientada: "Diz-se que uma ação é politicamente orientada quando e na medida em que tende a influir na direção de uma associação política, particularmente na apropriação ou expropriação, na nova distribuição ou atribuição dos poderes governamentais" ${ }^{\prime 6}$

55 VILLA, Rafael A. Duarte. Formas de influência das ONGs na política internacional contemporânea. Revista de Sociologia e Política, Curitiba, n. 12, p. 21-33, jun. 1999. Disponível em: <http://www.scielo.br/pdf/rsocp/n12/n12a02.pdf >. Acesso em: 3 mar. 2016

56 VILLA, Rafael A. Duarte. Formas de influência das ONGs 
Ora, tais características se coadunam harmoniosamente com os elementos formativos da concepção do DAG e descrevem um dos principais aspectos de sua possível contribuição para o contexto da problemática migratória internacional. Destarte a atuação das organizações não governamentais, entidades autônomas não vinculadas ao poder estatal e que atuam a partir do convencimento da sociedade internacional de que é possível uma atuação nova e diferenciada para o contexto da dramática situação migratória internacional.

Dentre aquelas que tem atuação global, podemos destacar a atuação do "Médicos Sem Fronteira" (MSF), organização humanitária internacional e independente que leva ajuda médico-humanitária a pessoas afetadas por conflitos armados, epidemias ou desastres naturais e que, recentemente, tem se envolvido com o resgate de refugiados perdidos em alto-mar. Existe ainda a "Anistia Internacional", movimento global independente e presente em mais de 150 países, criado há mais de cinco décadas e tem foco na preservação e promoção dos direitos humanos e o "Comitê Internacional da Cruz Vermelha", com mais de um século e meio de existência, com atuação em todos os continentes, com atuação em face das vítimas de confrontos armados.

O DAG ocupa-se da promoção da interação da atuação conjunta destas forças sociais, quer vinculadas ao poder estatal tradicional, ou às organizações internacionais de caráter diplomático como os comissariados da ONU para a questão migratória ou, ainda, a essas institucionais privadas ou híbridas e é exatamente nesse contexto que parece trazer em seu bojo, a maior possibilidade de influência na gestão supranacional destes problemas.

\section{Conclusões}

O tratamento da questão migratória está diretamente ligado com a problemática da segurança nacional e internacional. Todavia, a situação do imigrante deve ser tratada de uma perspectiva humanitária e o DAG poderia oferecer ferramentas para a regulação de soluções ágeis para a crise migratória atual.

A continuidade do tratamento dos fluxos migratórios somente do ponto de vista da segurança não ira

na política internacional contemporânea. Revista de Sociologia e Política, Curitiba, n. 12, p. 21-33, jun. 1999. Disponível em: <http://www.scielo.br/pdf/rsocp/n12/n12a02.pdf >. Acesso em: 3 mar. 2016. p. 23. contribuir para minimizar os efeitos da crise migratória, tendo ao contrácorroborio o efeito de agravá-la a partir de um reforço do sentimento de hostilidade e animosidade despertado na população nacional.

Existe, ainda, uma serie de duvidas a respeito da afirmação de que o fluxo migratório atue de maneira negativa sobre a realidade do emprego ou da seguridade local e, de igual modo, restou demonstrado que a situação de vulnerabilidade em que se encontra o imigrante ilegal tem forte influência sobre os crimes relacionados à exploração da pessoa humana, em todos os aspectos do tráfico de pessoas e, também, do terrorismo. A regularização da situação do imigrante, sua incorporação efetiva ao rol de direitos e deveres e à submissão plena ao ordenamento jurídico do país de origem, é ação que influencia diretamente na diminuição da vulnerabilidade dos agentes e, por conseguinte, na possibilidade de proteção estatal mais específica com a consequente inserção no contexto econômico do país de acolhimento, com reflexos substanciais na atividade econômica deste.

Os mecanismos e a forma de atuação do DAG, em especial em face da celeridade com que os problemas migratórios atuais precisam ser enfrentados, revelam-se altamente pertinentes a partir da atuação conjunta das forças públicas, estatais e internacionais e dos organismos internacionais de índole privada, a exemplo das organizações não governamentais.

\section{Referências}

ANDERSON, Bridget; DAVIDSON, Julia O'connell. Save the children publications: trafficking: a demand led problem? a multi-coutry pilot study. Stockholm. 2002. Disponível em: <http://gaatw.org/publications/The\%20 Demand\%20Side\%20part1.pdf>. Acesso em: 6 ago. 2015.

CARD, David. The impact of the mariel boatlift on the Miami labor market. Industrial and Labor Relations Review, Cambridge - MA, v. 43, n. 2, p. 9-41, jan. 1990.

DIAS, Guilherme Mansur. Migração e crime: desconstrução das políticas de segurança e tráfico de pessoas. 2014. Tese (Doutorado) - Universidade Estadual de Campinas, Campinas, SP, 2014.

FIREDBERG, Rachel; HUNT, Jennifer. Immigration will lower the wage more if immigrants are prepared to work for less than natives, as seems possible in the case of illegal immigrants, for example: an influxo $f$ such immigrants not only supply, but makes it more elastic. The Journal of Economic Perspectives, Nashville - TN, v. 9, n. 2, p. 23-44, abr. 1995. Diponível em: <http://www. 
researchgate.net/profile/Rachel_Friedberg/publication/4902369_The_Impact_of_Immigrants_on_Host_ Country_Wages_Employment_and_Growth/links/00b7d53510a07bb20b000000.pdf>. Acesso em: 1 ago. 2015.

GALLAGHER, Anne. Trafficking, smuggling and human rights: tricks and treaties. Forced Migration Review, Oxorfd-UK, n. 12, p. 25-28, abr/2002. Disponível em: <http://www.fmreview.org/FMRpdfs/FMR12/ fmr12.9.pdf $>$. Acesso em: 11 ago. 2015.

GRISWOLD, Daniel. Immigrants have enriched American culture and enhanced our influence in the world. Cato Institute. 2002. Disponível em: <http://www.cato.org/publications/commentary/immigrants-have-enriched-american-culture-enhanced-our-influence-world $>$. Acesso em: 14 out. 2015.

HEILMANN, Maria de Jesus Rodrigues Araújo. Globalização e o novo direito administrativo. Curitiba: Juruá, 2010.

HONG, Gihoon; MACLAREN, John. Immigrants appear to raise local non-tadables sector wages and to attract native-born workers form elsewhere in the country overall, it appears that local woerkers benefit form the arrival of more immigrants. In: NBER Working Paper Series. Are Immigrants a shot in the arm for the local economy? Cambridge, MA: NBER, 2015.

HUYSMANS, Jef. The European Union and the Securitization of Migration. Journal of Common Market Studies, Oxford - UK, v. 38, n. 5. p. 751-777, dez. 2000. Disponível em: <http://onlinelibrary.wiley.com/doi/10.1111/14685965.00263/pdf >. Acesso em: 13 out. 2015.

HYATT, Susan B. What was neoliberalism and what comes next? The transformation of citizenship in the law-and-order State . In: SHORE, Cris; WRIGHT, Susan; PERÒ, Davide (Ed.). Policy worlds: anthropology and the analysis of contemporary power. New York: Berghahn Book; Oxford, 2011.

KEMPADOO, Kamala. Shifting the debate on the traffic of womem. 2005. Disponível em: <http://www. scielo.br/scielo.php? script $=$ sci_arttext \&pid=S0104-83332005000200003\#top16>. Acesso em: 7 ago. 2015.
KEMPADOO, Kamala; SANGHERA, Jyoti; PATTANAIK Bandana. Trafficking and prostitution reconsidered: new perspectives on migration, sex work, and human rights. 2. ed. London: Paradigm Publishers, 2005.

KRISCH, Nico, KINGSBURY, Benedict. Introdução: governança global e direito administrativo global. Rio de Janeiro. RDA - Revista de Direito Administrativo, v. 261, p. 13-32, 2012.

PERI, Giovanni. Work papers series. Department of Economics UCDAVIS. Rethinking the area approch: immigrants and teh labor market in California, 1960-2005. California: Ed. Univ. of California, 2009.

SCHEPER-HUGHES, Nancy. Parts unknown: undercover ethnography of the organs-trafficking. Revista Ethnography. London - UK, v. 5, p. 28-73, may 2004.

SCHMIDT, Assmann. E. La Ciencia del derecho administrativo ante el reto de la internacionalización de las relaciones administrativas. Revista de Administrción Pública - RAP, Madrid, n. 171, p. 4-11, set./dez. 2006.

TIRMAN, John. Immigration and insecurity: post-9/11 fear in the United States. Massachusetts - USA: MIT Center for International Studies Audit of the Conventional Wisdom. p. 6-9, jun, 2006. Disponível em: <http://web. mit.edu/cis/pdf/Audit_Tirman_Immigration_6.06.pdf > Acesso em: 14 out. 2015.

TOMASSINI, L. El proceso de trasnacionalización y las relaciones externas de América Latina. Buenos Aires: Grupo Editor Latinoamericano, 1984.

TOMASSINI, L. El Trasnacionalización y desarrollonacional en América Latina. Buenos Aires: Grupo Editor Latinoamericano, 1984.

VILLA, Rafael A. Duarte. Formas de influência das ONGs na política internacional contemporânea. Revista de Sociologia e Politica, Curitiba, n. 12, p. 21-33, jun. 1999. Disponível em: <http://www.scielo.br/pdf/rsocp/ n12/n12a02.pdf>. Acesso em: 3 mar. 2016. 